depleted rhizomes, the formation of new buds for future rhizomes and fronds, for the production of spores and for the elongation of the perennating rhizome-its chief method of spreading. This may grow as much as a yard each year. In this way a 1/40 acre bracken plant could become an acre in extent in 34 years, or 24 such plants could invade 1,000 sq. yd. in a year.

Unfortunately, bracken possesses few natural insect and fungoid enemies, and none of these materially damages it when it is growing in congenial sites. The one effective measure of control is continuous destruction of the fronds, so that the rhizome is exhausted in forming new fronds. The best time is when the frond is almost completely unfolded (mid-June to early July). A second and even a third removal of the fronds may be necessary for the first two years; thereafter the plant is much weakened and a single cut per year for a further two to five years should exterminate it.

Until recently, fronds have been destroyed by the scythe or by the sickle at a rate of $0 \cdot 5-3$ acres per day, at a cost of $3 s .-8 s$. per cut per acre, and this on land probably worth only a shilling or two per acre. Now various machines have been produced, and this year the Department of Agriculture for Scotland has granted half the purchase price of machines (spread over three years) for areas satisfactorily cut with the Collins' power bracken cutter or the Glaslyn bracken cutter. The former can cut more than an acre an hour and the latter about an acre an hour, thus reducing the cost to approximately $1 s .6 d .-2 s$. $6 d$. per acre. This season other promising machines have been produced: $(a)$ the Denny hand scythe, (b) for horses or tractors, the Crossley thistle cutter and the Holt bracken breaker, and $(c)$ the Allan and the Gordon motor machines. Reports of a demonstration of these and the two former machines appeared in the North British Agriturist and the Scottish Farmer of September 3 and 5,1936 , respectively*, and results of their use over extensive areas will be awaited with interest.

The employment of chemical sprays and powders applied by autogiro, tractor, horse-sprayer or hand, has so far proved to be costly and clumsy compared with the cutting methods, and often the resulting growth of herbage is less satisfactory.

* The North British Agriculturist, 88, No. 37, 855 (1936). The Scottish Farmer, 44, No. 2277 (1936).

\title{
Developments in Electroplating
}

$\mathrm{W}$ ITH the ever-growing demand for materials possessing new and more varied combinations of properties, it is seldom that any one of the commoner metals has all the properties desired for special applications. Suitable mechanical strength may be offset by susceptibility to corrosion, suitable density by insufficient hardness, amenability to mechanical processing by unsatisfactory appearance. The use of alloys of two or more metals affords one important method of escape from these limitations, especially since a small addition of an alloying element often produces profound alterations of properties. On the other hand, since it is frequently only the surface properties which particularly need modification, an alternative method is to cover the surface with a suitable coating. Thus, the metal may be coated with various enamels, paints, or lacquers ; or with a thin layer of a different metal which may be applied by direct immersion in the molten metalas in the production of tin-plate or galvanized iron-by electrodeposition from a solution of a salt of the metal, or by other means.

The two ways of using a metal to modify the properties of another-as an alloying element and as a coating-have both been extensively ex- ploited, but their fields of application have seldom overlapped. Thus the range of utility of steel has been enormously extended by the use of coatings of tin, zinc and cadmium, but no alloys of these metals with steel have found application. Nickel has been used in both ways in relation to steel, but the applications of the respective products have been notably different. Indeed, chromium seems to be the only metal employed both for alloying with steel and as a coating on steel in order to produce the same type of result, namely, a tarnish-resisting surface.

These were among the matters discussed by $\mathrm{Mr}$. D. J. Macnaughtan in introducing a symposium on electroplating before Section B (Chemistry) of the British Association at the recent meeting in Blackpool. The other papers presented were "The Development of Control in Electrodeposition Processes", by Mr. A. W. Hothersall; "Electrodeposited Coatings as Corrosion Preventives", by Dr. S. Wernick; "Non-tarnishable Finishes", by Mr. E. A. Ollard; "Advances in Industrial Electroplating", by Mr. C. F. J. Francis-Carter ; and "The Future of Electrodeposition", by Dr. H. J. T. Ellingham. The whole group of papers afforded a survey of the development of electroplating 
practice, and directed attention to the striking advances which have been made in recent years. The achievements of modern electroplating were effectively illustrated by means of an exhibition specially arranged in conjunction with the meeting by the Electrodepositors' Technical Society.

In the more restricted sense of the term, electroplating connotes the electrodeposition of a thin, adherent coating of a metal over the surface of a metallic object in order to provide a decorative finish, to protect the underlying metal against corrosion, tarnish or wear, or to achieve a combination of these effects. The use of the term is often extended, however, to include a number of cognate electrolytic processes such as : the electrodeposition of relatively thick and very strongly adherent layers of metal for 'building up' worn or undersized machine parts; the production of adherent oxide coatings on aluminium and its alloys by anodic treatment (anodizing); and the electrodeposition of non-adherent layers of metal which, on detachment from the surface on which they are formed, faithfully reproduce details of surface structure (as in the production of electrotypes and gramophone matrices) or the complete shape of an object (electroforming).

Although electroplating became a commercial process nearly a century ago, developments during the last twenty years have been so important as to change completely the scope and status of the industry. The list of metals electrodeposited in plating practice has been extended by the important addition of chromium and, quite recently, of rhodium; and now comprises zinc, cadmium, tin, lead, iron, cobalt, nickel, chromium, copper, silver, gold, palladium, platinum and rhodium. The anodizing of aluminium and its alloys has been introduced; and progress has been made in the electrodeposition of two metals simultaneously, so as to produce alloy coatings such as copper-zinc, copper-tin and zinc-cadmium.

Apart from the introduction of new metals and new processes, there has been also an all-round improvement in the quality and reliability of electrodeposited coatings, and an enormous expansion of the range and scale of their applications. Electroplating is now practised as one of the regular series of operations involved in the manufacture of a large proportion of metal articles of industrial and domestic utility.

For the protection against corrosion of a wide range of iron and steel articles and fittings, electroplating with zinc or cadmium has become an important commercial process. Electrodeposited coatings of tin and, in special circumstances, of lead are also being used for this purpose ; and as a result of the new methods employed in rolling mills, whereby steel sheet is produced in the form of a continuous strip, electrodeposition of tin is now becoming a practicable alternative to 'hotdipping' in the large-scale manufacture of tin plate. Although the particular difficulties which beset the electrodeposition of adherent metal coatings on aluminium have been partly overcome, it is fortunate that, by anodic treatment of this metal and some of its alloys in suitable electrolytes, it is possible to bring about a considerable thickening of the oxide film which normally covers the surface, and thus effectively protect the underlying metal against corrosion. Since, moreover, the resulting oxide layer is a good insulator, is resistant to wear and readily takes up dyes-thus furnishing various decorative effects-it is not surprising that this anodizing process has rapidly found a wide range of applications.

The enormous expansion in the scale of nickelplating during the last twenty years-it is estimated that an area of about 250 million square feet is now deposited annually-must be partly attributed to the development of chromiumplating. While very thin coatings of chromium on steel are liable to be too porous to afford much protection against corrosion, and thicker deposits are likely to crack, a highly satisfactory tarnishresisting surface is produced by first coating the steel with a sound nickel deposit and then covering this with a 'flash' of chromium. In this two-stage process, which has been very widely adopted, it is most important that the nickel 'undercoat' shall be firmly adherent, uniform and non-porous ; and the thorough investigation of the factors which determine these properties has led to outstanding improvement in the quality and reliability of electrodeposited nickel coatings. The now widespread use of chromium as a non-tarnishing finish on base metals may be paralleled by the similar application of rhodium on the precious metals. Thus an extremely thin flash of this hard and highly resistant metal on silverware furnishes a lustrous surface, barely distinguishable in appearance from that of silver itself-but which does not require periodic cleaning.

In all these new developments important parts have been played by the metallurgist, the physicist, and especially the chemist. As a result of careful study of the functions of various ingredients in plating baths, considerable simplification of the older 'formulæ' has been effected, and it has become possible to exercise a much more exact control over conditions of operation, and hence over the character and properties of the deposit. The study of the influence of the $p \mathrm{H}$ value of solutions, especially in the deposition of nickel, has been important in securing adherent deposits free from pin-holes. Investigation of the factors which determine the 'throwing-power' of plating 
baths has led to the development of solutions which yield deposits of almost uniform thickness over the whole surface of an object of complicated shape. Examination of the effects of various kinds of 'addition agents' - especially colloids and other substances of high molecular weight-in the solution, has resulted in the production of smooth, coherent coatings from baths which otherwise yield coarsely crystalline, irregular or spongy deposits ; and is now leading to the direct production of coatings so lustrous as not to need polishing - a matter of some importance when the size or shape of the article or the nature of the deposit renders the polishing process difficult and costly, or where a particularly smooth surface is a necessary condition for the success of a subsequent process, such as the deposition of chromium on electrodeposited nickel.

The introduction of quantitative tests for such properties of the coating as hardness, porosity, internal stress and adhesion, has enabled these properties to be correlated with the conditions of deposition and hence to be brought under control. Microscopical examination of etched surfaces and sections has done much to indicate the size, shape and general arrangement of the crystallites of which the deposit is built up, and even to detect the presence of non-metallic matter, such as oxides, which may enter the deposit, probably in the colloidal state, and profoundly affect its properties. Such problems are now being further investigated by $\mathrm{X}$-ray and electron diffraction methods.

Although the thickness which an electrodeposit should attain in order to fulfil its purpose depends not only on the nature of the metal deposited but also on the character of the basis metal and the conditions of service to which it is to be subjected, the following values (expressed in thousandths of an inch) give a general indication of the thicknesses of various metal coatings used in ordinary practice : lead, 3 ; nickel and silver, 1 ; zinc, 0.5 ; cadmium, $0.3-0.5$; tin, $0.2-0.5$; oxide film on anodized aluminium, 0.04 ; chromium (over nickel), 0.02 ; gold, platinum, palladium, rhodium, less than 0.01 . These figures may be compared with 0.023 for the wave-length of sodium light and 0.0001 for the thickness of the air-formed 'passive' film on chromium, expressed in the same units.

The introduction of scientific control at every stage of electroplating processes, including the very important preliminary cleaning operations required to free the surface of the basis metal from traces of oxide, grease or other impurities which would prevent perfect adhesion of the coating, has raised the general standard of quality and reliability of plating to a remarkable extent, and given users confidence in its value for a wide range of new industrial purposes. The resulting increase in demand has stimulated the development of mass production methods for plating articles in automatic plants. The articles to be plated are carried at a regulated rate by conveyor chains through a suecession of tanks and chambers in which the operations of cleaning, washing, plating, rinsing and drying are conducted in their proper sequence and each for its appropriate time. Although the modern type of automatic plating plant dates back only to 1929, twenty-seven such plants are now working in Great Britain. They operate on the deposition of pure metals such as zinc, cadmium, tin, nickel, chromium, copper and silver ; of alloys such as copper-tin, copper-zinc and zinc-cadmium; and where no intermediate polishing is needed, successive deposits such as nickel and silver or copper and nickel may be produced in proper sequence ; or finishing processes such as 'oxidizing' or chemical colouring may be carried out at the conclusion of a plating operation. Such plants are often of very large capacity. Thus, whereas a few years ago a 500 gallon plating tank would have been considered very large, 3,000-5,000 gallon tanks are now common, and the largest plant now operated in Great Britain - a nickel plating planthas a tank capacity of 12,000 gallons, which represents about 60 tons of solution containing about $13 \frac{1}{2}$ tons of nickel sulphate.

Improved control of the electrodeposition process has also led to notable developments in fields somewhat outside that of standard electroplating practice, such as the deposition of hard, wearresistant facings on press tools, printing cylinders, gauges, etc.; the building up of worn machine parts; and the production of seamless metal tubing by depositing a thick, non-adherent coating of metal on a mandrel rotating in a plating bath. Cylindrical shells of copper deposited in this way may be slit up to form sheet, with mechanical properties superior to that of ordinary rolled sheet. By successive deposition of two metals, for example, copper and nickel, 'bi-metallic' sheet may also be produced.

With a continuance of the close co-operation which has now been established between the research laboratory and the plating shop, there is every reason to believe that all the lines of development referred to above will be extended. Additional metals will no doubt be introduced into plating practice, in some cases probably by the use of non-aqueous solutions; and the whole field of alloy deposition is only just beginning to be explored systematically. Methods of control of existing processes will be still further improved, and new developments in various other industries will undoubtedly open up a variety of new and hitherto unsuspected applications of electroplating. 